\title{
Tremor-nystagmus-duodenal ulcer syndrome
}

INSERM

\section{Source}

INSERM. (1999). Orphanet: an online rare disease and orphan drug data base. Tremornystagmus-duodenal ulcer syndrome. ORPHA:3350

Tremor-nystag mus-duodenal ulcer syndrome is a rare hyperkinetic movement disorder characterized by mild to severe, progressive essential tremor, nystagmus (principally horizontal), duodenal ulceration and a narcolepsy-like sleep disturbance. Refractive errors and cerebellar signs, such as gait ataxia and adiadochokinesia, may be associated. There have been no further descriptions in the literature since 1976. 